\title{
Gas Phase Fullerene Anions Hydrogenation by Methanol Followed by IRMPA Dehydrogenation
}

\author{
Jean-François Greisch,* Bernard Leyh, Françoise Remacle, ${ }^{\dagger}$ and \\ Edwin De Pauw \\ Department of Chemistry, University of Liège, Liège, Belgium
}

The characterization in the gas phase of the mechanisms responsible for hydride formation can contribute to the development of new materials for hydrogen storage. The present work provides evidence of a hydrogenation-dehydrogenation catalytic cycle for $\mathrm{C}_{60}^{--}$anions in the gas phase using methanol vapor at room temperature as hydrogen donor. The involvement of methanol in the reaction is confirmed by experiments using $\mathrm{CD}_{3} \mathrm{OD}$ and $\mathrm{CD}_{3} \mathrm{OH} . \mathrm{C}_{60}$ hydride anions with up to 11 hydrogen atoms are identified via elemental composition analysis using FT-ICR mass spectrometry. For the longer reaction times, partial conversion of the $\mathrm{C}_{60}$ hydride ions into oxygen containing ion products occurs. Dehydrogenation using infrared multiphoton activation with a $\mathrm{CO}_{2}$ laser restores the $\mathrm{C}_{60}^{--}$anions. (J Am Soc Mass Spectrom 2010, 21, 117-126) ( 2010 American Society for Mass Spectrometry

$\mathrm{H}$ ydrogen, easily generated from renewable energy sources, has great potential as a fuel. Its storage in the gas state, however, involves pressures of hundreds of atmosphere whereas cryogenic temperatures are required in the liquid state, limiting its use in portable applications. This has motivated research on hydrides, metal, organic, and carbon structures as potential hydrogen storage systems. Another method, however indirect, to store hydrogen is reforming of hydrogen from methanol or other liquid fuels. The present work highlights the reactivity under mild conditions of gas-phase fullerene anions and fullerene hydride anions with methanol vapor, discusses the formation of fullerene hydride anions and the hydrogen release/dehydrogenation using infrared multiphoton activation in the gas phase and at room temperature. Although gas-phase conditions may not be directly relevant to the use of hydrogen storage materials and direct methanol fuel cell membranes [1-4], they may contribute to the understanding of the mechanisms involved and, therefore, to their improvement. Few results have been reported up to now on the gas-phase reactivity of $\mathrm{C}_{60}$ mono-charged ions. $\mathrm{C}_{60}^{\bullet-}$ was reported to lack reactivity in the gas phase with $\mathrm{H}_{2} \mathrm{O},\left(\mathrm{CH}_{3}\right)_{2} \mathrm{CHOH}, \mathrm{CF}_{3} \mathrm{CH}_{2} \mathrm{OH}, \mathrm{C}_{2} \mathrm{H}_{5} \mathrm{COOH}$, and $\mathrm{CF}_{3} \mathrm{COOH}$ [5], but its reactivity with methanol has not been investigated. $\mathrm{C}_{60}^{\bullet+}$ was also observed to be essentially unreactive with alcohols and esters, such as

Address reprint requests to Dr. J.-F. Greisch, Physikalische Chemie, Karlsruhe Institute of Technology, 76131 Karlsruhe, Germany. E-mail: jean-francois.greisch@chemie.uni-karlsruhe.de

*Current address: Physikalische Chemie, 76131 Karlsruhe, Germany.

† Director of FNRS, Belgium.
$\mathrm{CH}_{3} \mathrm{OH}, \mathrm{C}_{2} \mathrm{H}_{5} \mathrm{OH}, \mathrm{CH}_{3} \mathrm{OCH}_{3}, \mathrm{C}_{2} \mathrm{H}_{5} \mathrm{OC}_{2} \mathrm{H}_{5}, \mathrm{c}-\mathrm{C}_{4} \mathrm{H}_{8} \mathrm{O}$, n- $\mathrm{C}_{3} \mathrm{H}_{7} \mathrm{OH}, \mathrm{i}-\mathrm{C}_{3} \mathrm{H}_{7} \mathrm{OH}$, and $\mathrm{H}_{2} \mathrm{O}$ [6]. One of the important features of the gas-phase hydrogenation process described here is that it occurs in the reaction cell of a mass spectrometer also used for the characterization and the subsequent dehydrogenation of the $\mathrm{C}_{60}$ hydride ions formed. Previous mass spectrometric studies involving field desorption (FD) [7, 8], desorption electron ionization (DEI) $[9,10]$, matrix-assisted laser desorption ionization (MALDI) [11, 12], and atmospheric pressure photoionization (APPI) [13] were mostly used to characterize the fullerene hydride cations and anions produced by various approaches. To our knowledge, the only reported successful hydrogenation of an azafullerene using a mass spectrometer was by Drewello and coworkers [14]. The synthetic approaches reported and leading to the formation of fullerene hydrides include the Birch reduction $[11,15,16]$, the Benkeser reduction [17], polyamine reduction [18, 19], reduction by diimides [20], hydroboration [21, 22], hydrogen transfer reduction [7, 11, 23, 24], photoreduction [25], transition-metal catalyzed hydrogenation [26-28], zincconcentrated hydrochloric acid reduction [9, 29, 30], $\mathrm{Zn}(\mathrm{Cu})$ reduction [31-33], hydrozirconation [34], hydrogen radical induced hydrogenation [35], electrochemical reduction [36-38], sonication [39], direct reduction by hydrogen [27, 40-43], and direct exposure to atomic hydrogen [44, 45]. Typically involving extreme conditions, with temperatures of several hundred Kelvin, pressures about several mega Pascal, or condensed phase condition $[7,15,21,22,46]$, they significantly differ from the hydrogenation conditions used here and leading to the addition of up to $11 \mathrm{H}^{\bullet}$ to $\mathrm{C}_{60}^{--}$ by reaction with methanol vapor at room temperature. 
Furthermore, typical dehydrogenation methods described in the literature include thermal activation $[7,9$, $16,47]$, transition-metal catalysts and photochemical catalytic dehydrogenation [48], and electrochemical oxidation [38]. Thermal decomposition of $\mathrm{C}_{60} \mathrm{H}_{\mathrm{x}}(\mathrm{x} \leq 36)$ into $\mathrm{C}_{60}$ with hydrogen release has been reported for temperatures ranging from 660 to $923 \mathrm{~K}[7,9$, 47] with, for the higher hydrogen contents, some degradation into various hydrocarbon species (methane, ethane, benzene, etc.) [9]. Electrochemical oxidation in solution has provided evidence of the electrochemical reversibility of $\mathrm{C}_{60}$ hydrogenation following cathodic reduction, and of $\mathrm{C}_{60} \mathrm{H}_{\mathrm{x}}$ dehydrogenation upon anodic oxidation [38]. The gas-phase produced fullerene hydrides, $\mathrm{C}_{60} \mathrm{H}_{\mathrm{x}}$, obtained by reaction with methanol (and also with partially and fully deuterated methanol) are here dehydrogenated by infrared multiphoton activation (IRMPA) in the ion-cyclotron resonance cell of the mass spectrometer.

\section{Experimental}

The [60]fullerene was purchased from MER Corporation (Tucson, AZ, USA) at a purity of $99.9 \%$. The HPLC grade toluene ( $+99 \%$ purity, water content $<0.01 \%$ ) and acetonitrile (LC-MS grade, water content $<0.02 \%$ ) were purchased from Biosolve (Valkenswaard, The Netherlands). The $\mathrm{CH}_{3} \mathrm{OH}$ (99.9\% purity, ACS spectrophotometric grade) was purchased from Sigma-Aldrich (St. Louis, $\mathrm{MO}, \mathrm{USA}$ ). The $\mathrm{CD}_{3} \mathrm{OD} \mathrm{NMR}$ grade deuterated solvent was purchased from Euriso-Top (Paris, France) and has a purity higher than $99.9 \% . \mathrm{CD}_{3} \mathrm{OH}$ $(99.8 \%$ D) was purchased from Sigma-Aldrich (St. Louis, MO, USA).

The experiments described in the present work were performed on a hybrid quadrupole-FT-ICR mass spectrometer APEX-Qe 9.4T (Bruker Daltonics, Billerica, MA, USA), equipped with a standard Apollo I electrospray source (Figure 1). A slightly rust colored solution of $\mathrm{C}_{60}$ in toluene:acetonitrile $(4: 1$ or $3: 2)$ was electrosprayed at a flow rate of $120 \mu \mathrm{L} / \mathrm{h}$ with the assistance of $\mathrm{N}_{2}$ as nebulizing gas $\left(250^{\circ} \mathrm{C}\right)$. After a while, the signal decreases due to $C_{60}$ tendency to precipitate within the injection capillary. Pure acetonitrile can then be used to elute $\mathrm{C}_{60}$ and obtain stable signal over long periods of time. Even though no differences were detected between the different electronebulization conditions used, the electrospray conditions for a given set of experiments were kept constant to allow comparison. For

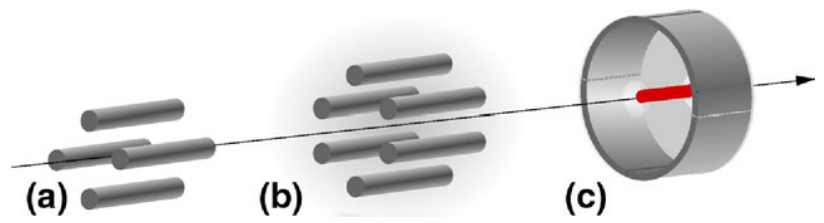

Figure 1. Experimental setup used in the present work: (A) quadrupole used for mass pre-selection, (B) reaction cell, (C) ICR cell where both infrared multiphoton activation and mass analysis take place. The arrow represents the timeline. all solution conditions used, the off axis needle was grounded with the end-plate and inlet capillary set to $3.54 \mathrm{kV}$ and $4.1 \mathrm{kV}$, respectively.

$\mathrm{C}_{60}^{\bullet-}$ ions formed in the source region of the mass spectrometer enter a quadrupole mass filter (Figure 1A), which selects either the full isotopic $\mathrm{C}_{60}^{\bullet-}$ distribution, or the signal corresponding to ${ }^{12} \mathrm{C}_{60}^{\bullet-}$ only. For the selection of the ${ }^{12} \mathrm{C}$ signal, since the characteristics of the quadrupole used do not allow to select only one isotopic peak, the selected $m / z$ was downshifted, with the upper $m / z$ cutoff shifted between the first and second isotopic peaks. The selected ions are then trapped within the reaction cell (Figure 1B) and allowed to react (hydrogenation step) with $0.1 \mathrm{~Pa}$ methanol $\left(\mathrm{CH}_{3} \mathrm{OH}\right)$ vapor at room temperature for well-defined periods of time ranging from $10 \mathrm{~ms}$ to $512 \mathrm{~s}$. Due to the elevated pressure, the ions thermalize quickly over very few seconds after entering the reaction cell, at a much faster rate than the hydrogen addition processes. Methanol vapor at $20^{\circ} \mathrm{C}$ continuously diffuses within the reaction cell via a nozzle valve. A pressure at the vacuum gauge adjacent to the reaction cell of $500 \pm 10 \mu \mathrm{Pa}$ is maintained throughout the experiments. Accurate pressure measurements directly within the reaction cell are currently not possible on the instrument in operating mode. The values measured on the vacuum gauge used in operating mode have been correlated to those obtained from a second vacuum gauge positioned directly on the reaction cell while the instrument was in nonoperating mode. The bias induced by this approach leads to a low accuracy but high precision estimate of $100 \pm$ $50 \mathrm{mPa}$ for the pressure measured in the reaction cell. Pressure fluctuations are well below 5\% for all measurements performed. After ejection from the reaction cell, the ion packet now containing fullerene hydrides is dynamically trapped (no side-kick used) in the ion cyclotron resonance (ICR) cell (Figure 1C) of the mass spectrometer. There, they can be either mass selected and/or undergo IRMPA (dehydrogenation step) using the laser intensity delivered by a continuous wave Synrad $48-2 \mathrm{CO}_{2}$ laser operated at $50 \%$ of its nominal power (commercial setup provided by Bruker, operated at $\sim 20 \mathrm{~W} / \mathrm{cm}^{2}$ and $\left.10.6 \mu \mathrm{m}\right)$, through a $\mathrm{BaF}_{2}$ window, for irradiation times of several hundreds of ms before detection. The whole hydrogenation-dehydrogenation cycle (shown as an insert in Figure 2) can then be repeated with a new bunch of ions. Indication of the overlap between the ions within the ICR cell and the IR beam is provided by the complete dissociation of the species stored upon a $0.6 \mathrm{~s}$ irradiation time (see Figure 2 and Figure 5). The total amount of energy deposited in the ions is, however, not known. Neither electron detachment nor fragmentation of $\mathrm{C}_{60}^{-}$anions were observed at this power even for irradiation times of $1.2 \mathrm{~s}$. A detailed investigation of the fluence/intensity dependence of the IRMPA dehydrogenation will be given in a subsequent paper.

In FT-ICR mass spectrometry one should ideally use FT absorption-mode spectral peak areas to determine 


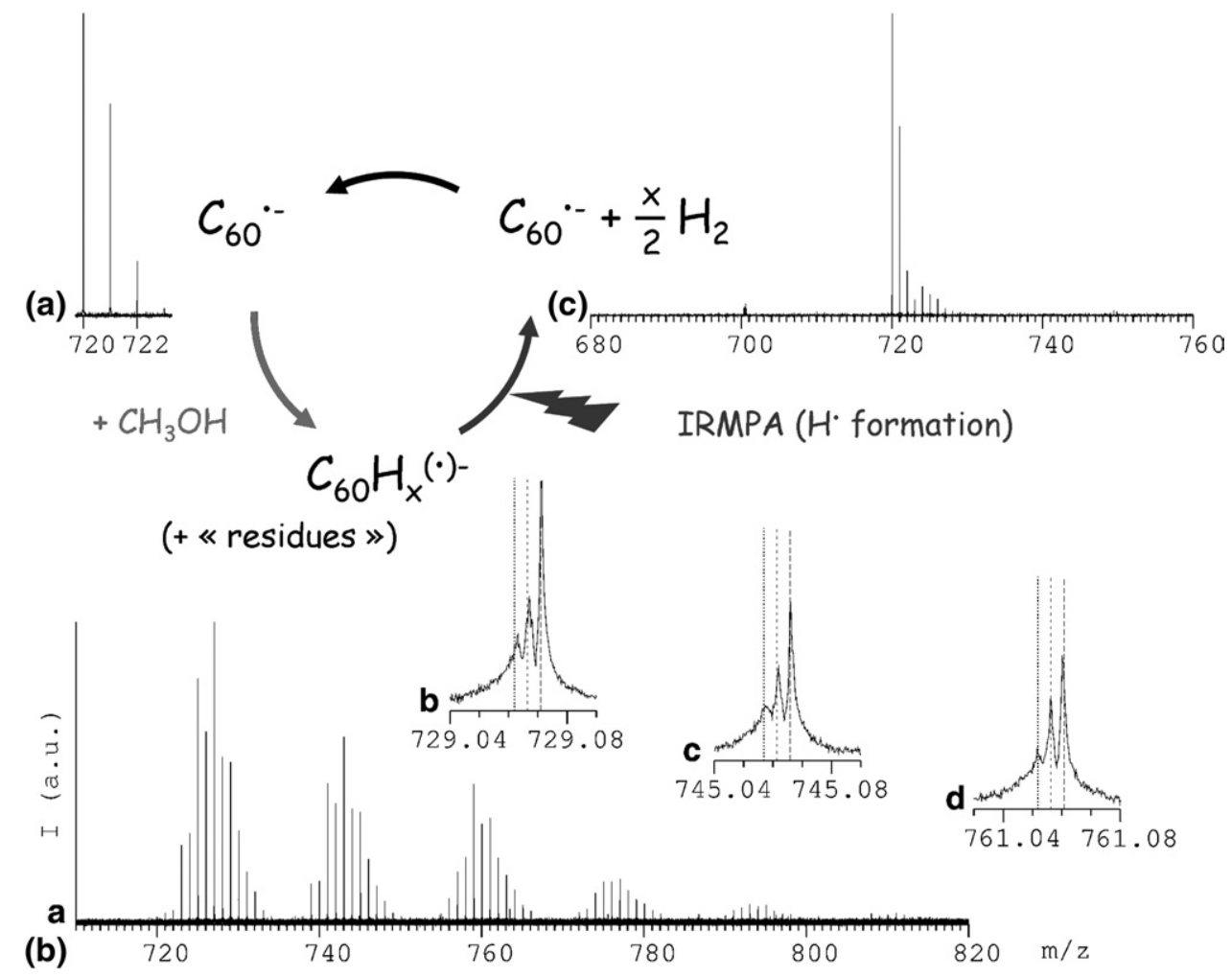

Figure 2. $\mathrm{C}_{60}^{\bullet-}$ full isotopic signal before (A) and after reaction with $\mathrm{CH}_{3} \mathrm{OH}$ for $512 \mathrm{~s}$ at room temperature $\left(20 \pm 1{ }^{\circ} \mathrm{C}\right)$ at a pressure of about $0.1 \mathrm{~Pa}(\mathbf{B}-\mathrm{a})$. The scale-ups $(\mathbf{B}-\mathrm{b}, \mathbf{B}-\mathrm{c}$, and $\mathbf{B}-\mathrm{d})$ make elemental composition determination possible. The dashed vertical lines drawn in scale-up (B-b) correspond from left to right to ${ }^{12} \mathrm{C}_{58}{ }^{13} \mathrm{C}_{2} \mathrm{H}_{7}^{-},{ }^{12} \mathrm{C}_{59}{ }^{13} \mathrm{CH}_{8}^{\cdot-}$, and ${ }^{12} \mathrm{C}_{60} \mathrm{H}_{9}^{-}$. Their equivalents are also drawn in scale-ups (B-c) and (B-d) describing species respectively containing one and two oxygen atoms. Spectrum (C) represents the result of $1.2 \mathrm{~s} \mathrm{cw}$ infrared multiphoton activation (IRMPA) $(\sim 20 \mathrm{~W})$ applied to an ion mixture corresponding to the $(\mathrm{B}-\mathrm{a})$ spectrum. No evidence of $\mathrm{C}_{60}$ fragmentation is observed.

the relative numbers of different species [49]. In a frequency-domain spectrum obtained by discrete Fourier transformation (FFT) of the time-domain response following a $\delta$-function excitation, the absorption-mode spectral peak relative areas are directly proportional to the time-domain relative initial amplitudes of the sinusoidal signals, which in turn are proportional to the numbers of oscillators at those frequencies [49]. However, it is not always possible to phase-correct a complex FT spectrum to obtain its pure absorption-mode component. This results in unavoidable auxiliary "wiggles" in each spectral peak [49]. In the present work, the peak intensities, as defined in DataAnalysis 3.4 (Bruker) - not the peak areas-were used to determine the relative numbers of different species.

The mass spectra were internally calibrated, and the elemental composition assignments were based on accurate mass measurements. The mass resolving power is typically very high $(100,000-700,000)$ and mass accuracy is typically better than $1.0 \mathrm{ppm}$.

\section{Results and Discussion}

Reaction of the full isotopic signal of $\mathrm{C}_{60}^{\cdot-}$ (Figure 2A) for $512 \mathrm{~s}$ with $\mathrm{CH}_{3} \mathrm{OH}$ at room temperature yields the mass spectrum of Figure 2B-a, in opposition to $\mathrm{C}_{60}^{\cdot+}$ found to be unreactive to methanol [6]. Elemental composition determination allows us to identify the different isotopic distributions (Figures 2B-b, B-c, and $\mathrm{B}-\mathrm{d}$ ) and the hydrogenation extent. The isotopic distributions below $736 \mathrm{~m} / \mathrm{z}$ correspond to fullerene hydrides, $\mathrm{C}_{60} \mathrm{H}_{x}^{-}$, exclusively, with a maximum of eleven added hydrogen atoms detected. The higher $\mathrm{m} / \mathrm{z}$ isotopic distributions correspond to $\mathrm{C}_{60} \mathrm{H}_{\mathrm{x}} \mathrm{O}_{\mathrm{y}}^{-}$with $\mathrm{y}>0$. The three high-resolution scale-ups of Figure $2 \mathrm{~B}$ illustrate the contributions to the ion signal of ${ }^{12} \mathrm{C}_{58}{ }^{13} \mathrm{C}_{2} \mathrm{H}_{7}^{-}$, ${ }^{12} \mathrm{C}_{59}{ }^{13} \mathrm{CH}_{8}^{--}$, and ${ }^{12} \mathrm{C}_{60} \mathrm{H}_{9}^{-}$(Figure $2 \mathrm{~B}-b$ ) and their equivalent for species containing one (Figure $2 \mathrm{~B}-\mathrm{c}$ ) and two (Figure 2B-d) oxygen atoms. The presence of oxygen containing adducts pertains to the formation of fullerenols and degradation of fullerene hydrides into fullerenols $[20,50]$. In the present conditions, it has to involve either direct abstraction of hydroxyls by the fullerene or the substitution of hydrogen atoms on the fullerene by hydroxyls. Direct addition of $\mathrm{O}^{\bullet}$ or $\mathrm{O}_{2}$ is expected to be negligible due to their very low partial pressure within the reaction cell. The mass spectra of the hydrides formed upon reaction of $\mathrm{C}_{60}^{-}$ions with $\mathrm{CH}_{3} \mathrm{OH}$ and with $\mathrm{CD}_{3} \mathrm{OD}$ during $256 \mathrm{~s}$ are compared in Figure 3. The absence of $m / z=721$ in Figure 3B already shows that no 


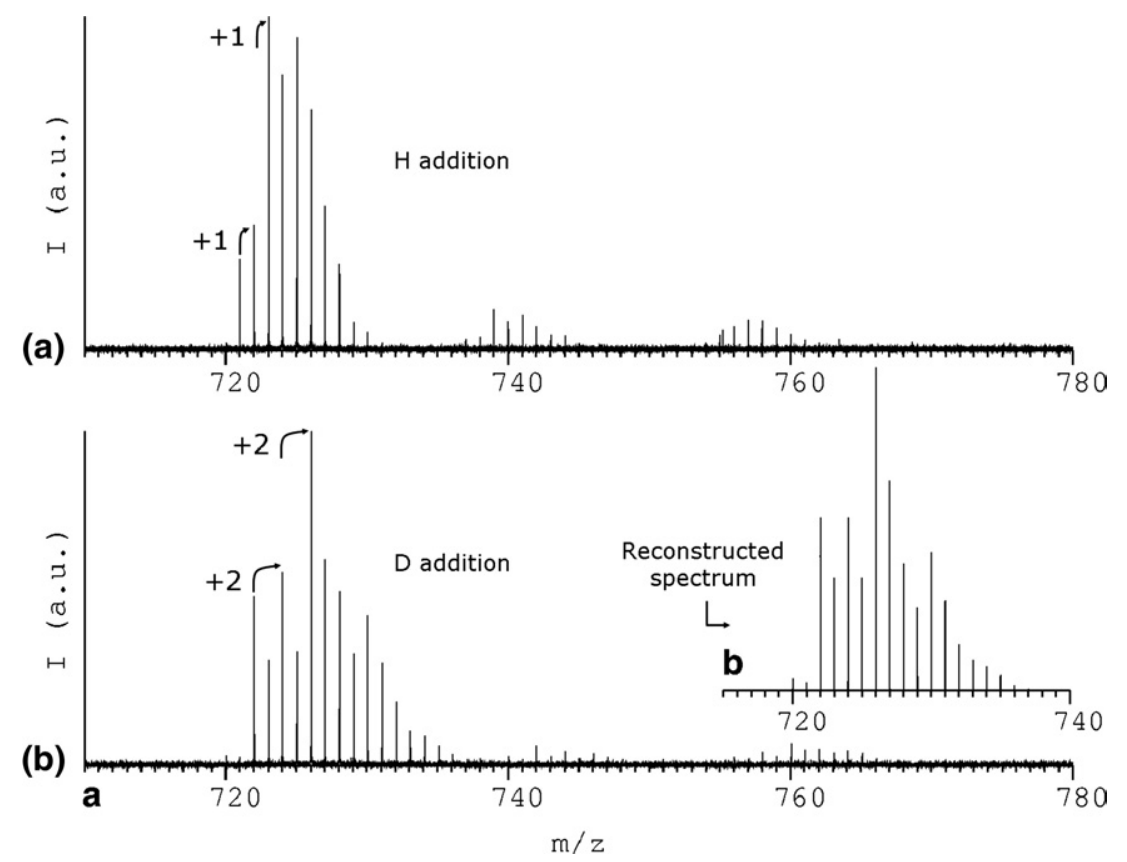

Figure 3. Reaction of $\mathrm{C}_{60}^{\cdot-}$ full isotopic signal with $\mathrm{CH}_{3} \mathrm{OH}(\mathbf{A})$ and $\mathrm{CD}_{3} \mathrm{OD}(\mathbf{B}-\mathrm{a})$ for $256 \mathrm{~s}$ at room temperature $\left(20 \pm 1^{\circ} \mathrm{C}\right)$ and at a pressure of about $0.1 \mathrm{~Pa}$. The $\mathrm{C}_{60} \mathrm{D}_{\mathrm{x}}$ distribution pattern with $\mathrm{m} / \mathrm{z}=$ 2 increments is characteristic of the exclusive addition of deuterium. The high purity of the $\mathrm{CD}_{3} \mathrm{OD}$ used and the absence in spectrum $\mathbf{B}$ of signal at $721 \mathrm{~m} / \mathrm{z}$ that would correspond to $\mathrm{C}_{60} \mathrm{H}^{-}$, support hydrogen abstraction from methanol. $(\mathbf{B}-\mathbf{b})$ is the theoretical distribution obtained by linear combination of eight $C_{60}$ isotopic distributions each shifted by two mass units with weights: $1,15,15,28,11$, $12,4,2$.

$\mathrm{H}$ addition takes place when $\mathrm{CD}_{3} \mathrm{OD}$ is used. The observed hydrogenation extent is similar for the two reagents and reaches 9 and 8 , respectively. Note that the signal observed in Figure $3 \mathrm{~B}$ is the superposition of mainly two components, ${ }^{12} \mathrm{C}_{60} \mathrm{D}_{\mathrm{x}}^{-}$(even $\mathrm{m} / \mathrm{z}$ ) and ${ }^{12} \mathrm{C}_{59}$ ${ }^{13} \mathrm{C}_{\mathrm{x}}^{-}$(odd $\mathrm{m} / \mathrm{z}$ ) because the full isotopic signal has been selected. This explains the intensity pattern of the odd and even $m / z$ peaks and confirms that only $\mathrm{D}$ is added in Figure 3B. The reconstructed mass spectrum, taking into account the isotopic distribution of $\mathrm{C}_{60}$, is shown as an inset in Figure 3B. Excellent agreement with the experimental spectrum (Figure 3B-a) is obtained.

Information about the kinetics of the successive hydrogenation steps can be extracted using a model described in Figure 4 . With a pressure in the $\mu$ bar range within the constant flow reaction cell, methanol can be considered to be in large excess compared with the ions, leading to successive pseudo first-order hydrogenation reactions, $k_{1 s t}=k_{2 n d}\left[\mathrm{CH}_{3} \mathrm{OH}\right]$. Assuming, as mentioned above, that the methanol pressure is $0.1 \mathrm{~Pa}$, and using an appropriate model discussed below to extract the $k_{1 s t}$ rate constant, the $k_{2 n d}$ bimolecular rate constants for the successive hydrogenation steps could be inferred. Only $\mathrm{C}_{60}^{\bullet-}$ anions with up to seven hydrogen atoms added are explicitly considered in the model. The signals of all other ions $\left(\mathrm{C}_{60} \mathrm{H}_{\mathrm{x}>7}, \mathrm{C}_{60} \mathrm{H}_{\mathrm{x}} \mathrm{O}_{\mathrm{y}>1}\right)$ are summed up and included in a residual contribution with the rate constants leading to the formation of the oxygen containing species starting from the $\mathrm{C}_{60} \mathrm{H}_{0 \leq x \leq 7}^{-}$ions explicitly considered. The total ion intensity is normalized to one and neutralization of fullerene anions is neglected (we found no experimental evidence of this reaction channel). To accurately measure the relative ion populations for $\mathrm{C}_{60} \mathrm{H}_{\mathrm{x}}^{(\bullet)-}$ with $\mathrm{x}=0-7$, it is necessary to avoid the ${ }^{13} \mathrm{C}$ contributions to the ion intensities. The ${ }^{12} \mathrm{C}_{60}^{\bullet-}$ ions were thus mass selected and reacted with $\mathrm{CH}_{3} \mathrm{OH}$ for 14 time periods ranging from $10 \mathrm{~ms}$ to $256 \mathrm{~s}$, four of which are shown in Figure 5. The conclusions obtained for ${ }^{12} \mathrm{C}_{60}^{\bullet-}$ are expected to hold also for ${ }^{13} \mathrm{C}$ containing anions. The highest level of hydrogenation for ${ }^{12} \mathrm{C}$ isotopically pure ${ }^{12} \mathrm{C}_{60} \mathrm{H}_{\mathrm{x}}^{-}$and ${ }^{12} \mathrm{C}_{60} \mathrm{H}_{\mathrm{x}} \mathrm{O}^{-}$, confirmed by elemental composition analysis (error $<0.5 \mathrm{ppm}$ ) also corresponds to 11 hydrogen atoms added and the infrared multiphoton activation during $1.2 \mathrm{~s}$ and for $\sim 20 \mathrm{~W}$ laser intensity at $10.6 \mu \mathrm{m}$ yields back the ${ }^{12} \mathrm{C}_{60}^{\bullet-}$.

Each $\mathrm{C}_{60} \mathrm{H}_{\mathrm{x}}^{-}(\mathrm{x}=0-7)$ ion is potentially involved in two kinds of reactions with methanol, respectively yielding $\mathrm{C}_{60} \mathrm{H}_{\mathrm{x}+1}^{\bullet-}$ with rate constant $\mathrm{k}_{\mathrm{x}+1}$ and $\mathrm{C}_{60} \mathrm{H}_{\mathrm{u}} \mathrm{O}_{\mathrm{y}}^{-}(\mathrm{u}=\mathrm{x}$ or $\mathrm{x}+1, \mathrm{y}>0)$ with rate constant $\mathrm{r}_{\mathrm{x}+1}$ (Figure 4). The rate constants (see Figure 4 and Table 1) leading to $\mathrm{C}_{60} \mathrm{H}_{\mathrm{x}}^{-}(\mathrm{x}=1-7)$ and $\mathrm{C}_{60} \mathrm{H}_{\mathrm{u}} \mathrm{O}_{\mathrm{y}}[\mathrm{y}>0$ or $(\mathrm{y}=$ 0 and $u>7$ )] are obtained from the fit (Figure 6) of the relative population of ions measured at 14 different times. Direct formation of $\mathrm{C}_{60} \mathrm{H}_{\mathrm{x}+2}^{-}$and formaldehyde, a by-product detected in direct methanol fuel cells (DMFCs) [51], upon transfer of two hydrogen atoms from one methanol molecule yield, when inserted into the 


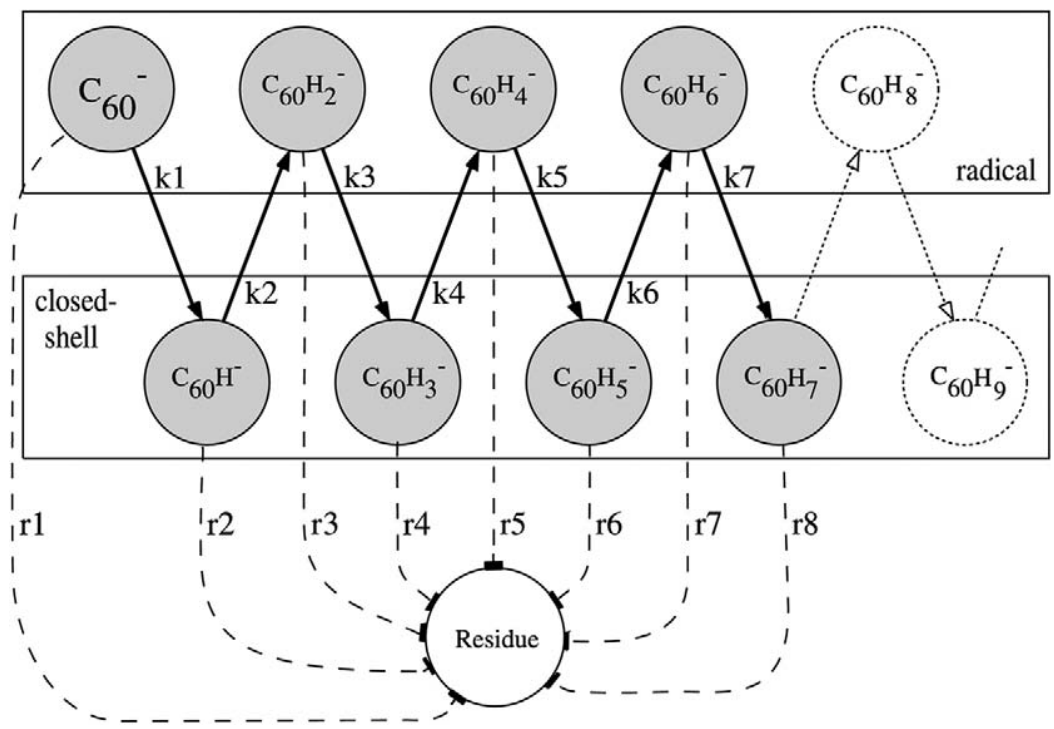

Figure 4. Kinetic model used to describe the formation of fullerene hydrides from $\mathrm{C}_{60}^{\bullet-}$ by reaction with $\mathrm{CH}_{3} \mathrm{OH}$. Each $\mathrm{C}_{60} \mathrm{H}_{\mathrm{x}}^{-}(\mathrm{x}=1-7)$ reagent is assumed to be involved in two different reactions, respectively, yielding $\mathrm{C}_{60} \mathrm{H}^{\circ}-$ and $\mathrm{C}_{60} \mathrm{H}_{\mathrm{u}} \mathrm{O}_{\mathrm{y}}^{-}(\mathrm{u}=\mathrm{x}$ or $\mathrm{x}+1)$, with rate constants labeled $\mathrm{k}_{\mathrm{i}}$ and $\mathrm{r}_{\mathrm{i}}(\mathrm{i}=$ $x+1)$. Only $\mathrm{C}_{60} \mathrm{H}_{\mathrm{x}}^{-}(\mathrm{x}=1-7)$ are explicitly considered due to increasing errors on the intensities measured and the inferred rate constants for $x>7$. "Residue" represents all the reaction products detected that do not qualify as $\mathrm{C}_{60} \mathrm{H}_{\mathrm{x}}^{-}(\mathrm{x}=1-7)$. This includes the oxygen containing species whose amount only becomes significant for the longer reaction times.

model, negligible rate constants and has been ruled out. The $\mathrm{C}_{60} \mathrm{H}_{\mathrm{x}}^{-}$ions can be organized in two groups corresponding to radical (x even) and to closed-shell (x odd) ions, respectively.

The ion intensities corresponding to three independent sets of experiments were then fitted to the kinetic model of Figure 4 using the MATLAB multi-experiment fitting toolbox PottersWheel [52]. The inferred reaction rates are reported in Table 1 while the semilog plot of the normalized ion intensities is reported in Figure 7.

The magnitude of bimolecular rate constants observed (see Table 1) is not unexpected, taking into account that the observed reaction times are of the order of tens of seconds and that the pressure conditions used lead to a methanol concentration of $2.510^{13}$ molecules $/ \mathrm{cm}^{3}$.

The low values of the fitted bimolecular rate constants are linked to a fairly negative entropy of activation. Using the transition-state theory expression for the bimolecular rate constant,

$$
k_{2 n d}=\frac{k_{B} T}{h} \bar{V}^{\circ} \exp \left(2+\triangle S^{\circ \ddagger} / R\right)
$$

where $\bar{V}^{\circ}$ is the standard molar volume, activation entropies, $\Delta S^{\circ \ddagger}$, in the range -180 to $-170 \mathrm{Jmol}^{-1} \mathrm{~K}^{-1}$ are derived. These values are not unreasonable for a bimolecular reaction even if they show that the transition state is very tight. The loss of three translational degrees of freedom when methanol interacts with the fullerene surface already accounts for an entropy loss of $152 \mathrm{Jmol}^{-1} \mathrm{~K}^{-1}$. Additional contributions could also come from the hindrance of the $\mathrm{OH}$ internal rotation or of bending motions of methanol.
However, the small rates constant observed could imply that impurities present in traces might also contribute to the hydrogenation of the $\mathrm{C}_{60}$ anions. The purity of the different methanol isotopomers used does not unambiguously allow assignment of methanol as the only hydrogen source, due to the possible presence of deuterated impurities. If impurities are involved, this would nevertheless imply that their abundance is comparable for the different methanol samples used and that their related reaction rates are several orders of magnitude higher than those reported here. To relax this issue somewhat, the same measurements were performed with water since it is the most abundant impurity. As observed by Squires and coworkers [5], no abstraction of hydrogen from $\mathrm{H}_{2} \mathrm{O}$ (ULC-MS; Biosolve, The Netherlands) was observed with the current setup for $\mathrm{C}_{60}$ anions and reaction times as long as $512 \mathrm{~s}$. Therefore, although contributions from impurities cannot be completely ruled out, they are deemed unlikely. It is suggested that additional measurements on a setup allowing in situ monitoring of the reagent gases/vapors used and allowing the ions to react while trapped (as it is the case here), be performed to fully relax this issue and confirm the magnitude of the reaction rates reported here.

The comparison of $k_{\text {even }}$ with $k_{\text {odd }}$ (Table 1) shows that the reaction rates for hydrogenating radical species $\left(\mathrm{k}_{\text {odd }}\right)$ are greater than those involving closed-shell ions $\left(\mathrm{k}_{\text {even }}\right)$. This result is in agreement with previous reports. The first evidence of a different behavior between fullerene hydride ions with odd and even masses, i.e., between closed-shell and radical species, was provided by mass spectrometry using laser desorption ionization. 
a

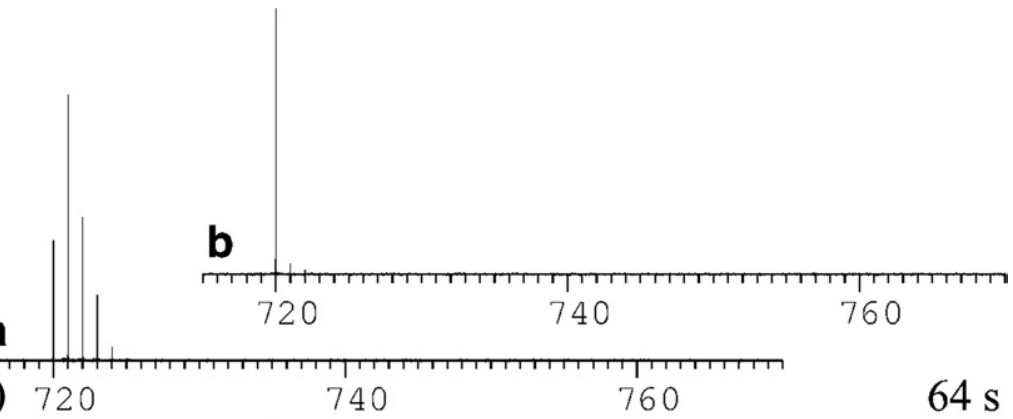

(a) 720

740

760

$64 s$

b

a

$\mid$

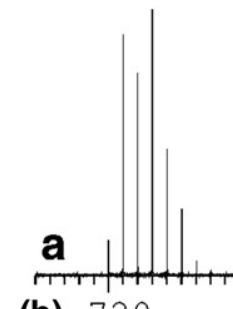

720

760

(b) 720

740

760

$128 \mathrm{~s}$

a

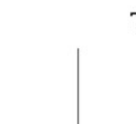

(1)

760

(c) 720

\section{b}

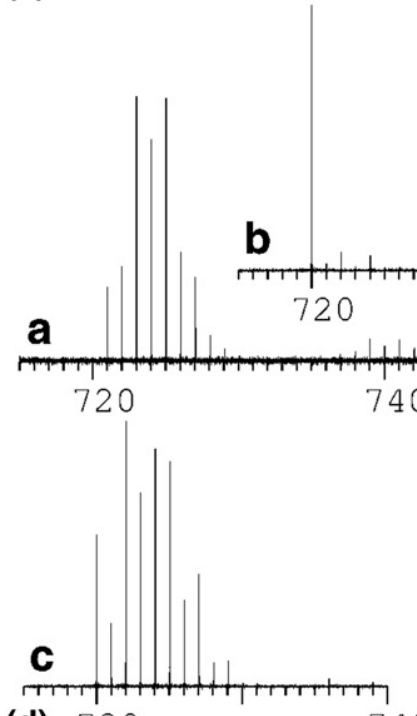

740

760

$192 \mathrm{~s}$

(d) 720

740

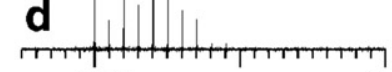

Figure 5. Mass spectra of the product ions formed by reacting ${ }^{12} \mathrm{C}_{60}^{\bullet-}$ with $\mathrm{CH}_{3} \mathrm{OH}$ for $64 \mathrm{~s}(\mathrm{~A}-\mathrm{a}), 128 \mathrm{~s}$ (B-a), $192 \mathrm{~s}(\mathbf{C}-\mathrm{a})$, and $256 \mathrm{~s}(\mathbf{D}-\mathrm{a})$. The spectra (A-b), (B-b), (C-b), (D-b) correspond to the result of $1.2 \mathrm{~s}$ infrared multiphoton activation (IRMPA) of the previous ion signals with recovery rates (ion signal after IRMPA/ion signal before) of $83 \%, 88 \%, 108 \%, 106 \%$, respectively, (the rates $>100 \%$ are a consequence of the uncertainty on the intensities of the oxygen containing species). Per se, the residual signal of ${ }^{13} \mathrm{C}$ containing species is negligible; it amounts to less than $2.5 \%$ of the total ion signal. The mass spectra (D-c) and (D-d) result of the IRMPA during $0.6 \mathrm{~s}(\mathbf{D}-\mathrm{c})$ and $0.8 \mathrm{~s}(\mathbf{D}-\mathrm{d})$ of the ion signal reported in (D). 
Table 1. Bimolecular reaction rate constants (in $10^{-16}$ $\mathrm{cm}^{3} \cdot$ molecule ${ }^{-1} \cdot \mathrm{s}^{-1}$ ) obtained for the reaction model described in Figure 4 and for an estimated value of the methanol vapor pressure of $1.0 \pm 0.5 \mu \mathrm{bar}=0.1 \pm 0.05 \mathrm{~Pa}$

\begin{tabular}{ccccc}
\hline $\mathrm{l}$ & $\mathrm{k}_{\mathrm{i}}$ & $\sigma\left(\mathrm{k}_{\mathrm{i}}\right)$ & $\mathrm{r}_{\mathrm{i}}$ & $\sigma\left(\mathrm{r}_{\mathrm{i}}\right)$ \\
\hline \hline 1 & 11.7 & 0.8 & 0.0 & 0.0 \\
2 & 6.1 & 0.4 & 0.0 & 0.0 \\
3 & 9.3 & 0.8 & 0.0 & 0.4 \\
4 & 6.1 & 0.8 & 0.0 & 0.4 \\
5 & 7.7 & 0.4 & 0.8 & 1.2 \\
6 & 6.1 & 0.4 & 0.0 & 0.0 \\
7 & 6.9 & 2.0 & 2.8 & 4.0 \\
8 & - & - & 4.9 & 3.6 \\
\hline
\end{tabular}

$\mathrm{k}_{\mathrm{i}}$ corresponds to the rate constant associated with the addition of one hydrogen to $\mathrm{C}_{60} \mathrm{H}_{\mathrm{i}-1}$ that leads to the formation of $\mathrm{C}_{60} \mathrm{H}_{\mathrm{i}} \sigma\left(\mathrm{k}_{\mathrm{i}}\right)$ is the standard deviation associated to $k_{i}$. The $r_{i}$ are the rate constants associated with the formation of the oxygen containing species $\mathrm{C}_{60} \mathrm{H}_{u} \mathrm{O}_{\mathrm{y}}^{-}(\mathrm{u}=\mathrm{i}$ or $\mathrm{i}+1)$ and are required for the closure of the system of equations (see Figure 4). $\sigma\left(r_{i}\right)$ is the standard deviation associated to $r_{i}$. Due to the low accuracy (but high precision) of the pressure measurement, the rate constants are affected by a large absolute uncertainty (see text).

Dissociative ionization of even numbered hydrogencontaining fullerene and facile protonation were suggested to occur to explain the dominant odd-numbered hydrogen-containing peaks $[12,13,16,40]$ observed under most ionization conditions. In the present case, the difference between $k_{\text {even }}$ and $k_{\text {odd }}$ is assigned to a difference of reactivity between closed-shell and openshell systems. It is seen to decrease as the number of hydrogen increases, with the open-shell rate constant values $\left(\mathrm{k}_{\text {odd }}\right)$ asymptotically tending to that of the closed-shell rate constant $\left(\mathrm{k}_{\text {even }}\right)$. This can be tentatively interpreted as an increase in the charge localization with the number of hydrogen atoms added, similar to that for closed-shell hydrides, which are fullerene mono-charged anions with an odd number of hydrogens, as further discussed in the next section.

Based on the available results, the addition mechanism is expected to yield fullerene hydride anions and the radical $\mathrm{CH}_{2} \mathrm{OH}^{\bullet}\left(\mathrm{CH}_{2} \mathrm{OH}^{\bullet}\right.$ has the lowest enthalpy of formation, $\Delta_{\mathrm{f}} \mathrm{H}\left(\mathrm{CH}_{2} \mathrm{OH}^{*}\right)=-9 \pm 4 \mathrm{~kJ} / \mathrm{mol} \mathrm{com-}$ pared with $\left.\Delta_{\mathrm{f}} \mathrm{H}\left(\mathrm{CH}_{3} \mathrm{O}^{\circ}\right)=17 \pm 4 \mathrm{~kJ} / \mathrm{mol}\right)$ [53]. When pure isotopic $\mathrm{C}_{60}^{-}$is reacted with $\mathrm{CD}_{3} \mathrm{OH}$ (Figure 8), the mass distribution of the fullerene hydrides is observed to extend up to higher values than with $\mathrm{CH}_{3} \mathrm{OH}$, indicating that $\mathrm{D}$ is actually added, a result compatible to the higher stability of $\mathrm{CD}_{2} \mathrm{OH}^{*}$. However, the spectrum shows also the addition of $\mathrm{H}$. Due to the impossibility to resolve a $\mathrm{H}$ pair from $\mathrm{D}$ on our instrument, even when the ${ }^{12} \mathrm{C}_{60}^{\cdot-}$ signal is selected (Figure $8 \mathrm{~B}$ ), the hydrides exact composition of a given peak (number of $\mathrm{H}$ and $\mathrm{D}$ added) cannot be determined. Therefore, either both $\mathrm{D}$ and $\mathrm{H}$ are abstracted from $\mathrm{CD}_{3} \mathrm{OH}$
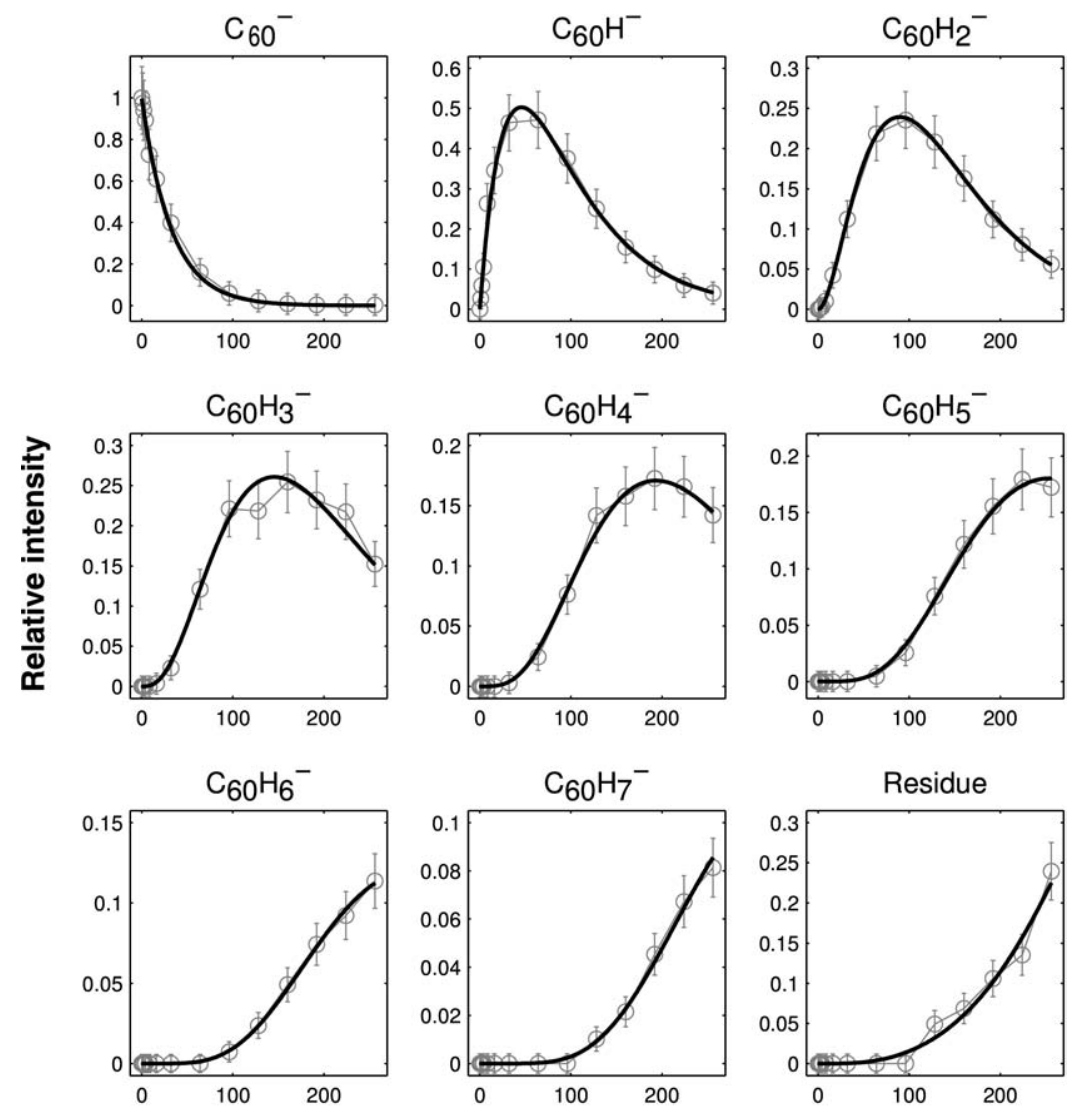

Reaction time (s)

Figure 6. Example of normalized ion intensities fitted using the model of Figure 4. 


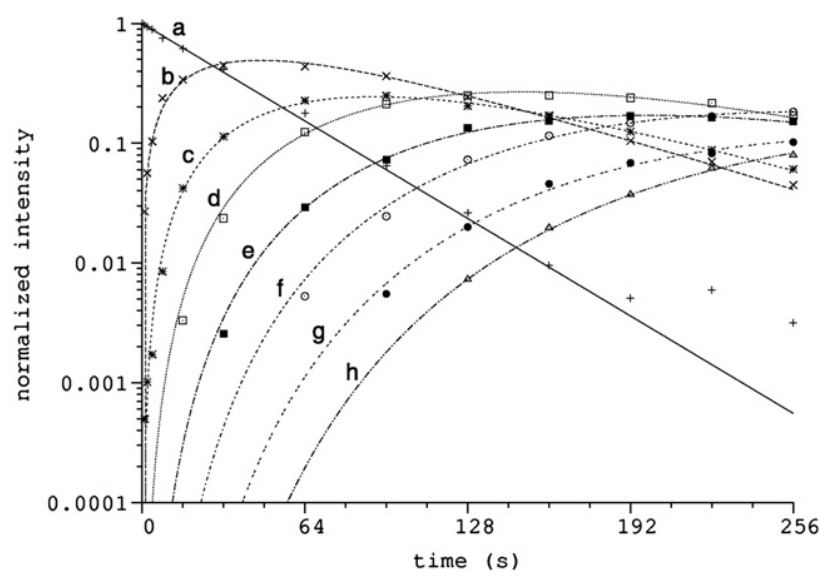

Figure 7. Semilog plot of the normalized ion intensities. The data points correspond to the measurements means while the lines correspond to the best fits obtained from the kinetic model used. (a) $\mathrm{C}_{60}^{\cdot-}$, (b) $\mathrm{C}_{60} \mathrm{H}^{-}$, (c) $\mathrm{C}_{60} \mathrm{H}_{2}^{--}$, (d) $\mathrm{C}_{60} \mathrm{H}_{3}^{-}$, (e) $\mathrm{C}_{60} \mathrm{H}_{4}{ }^{--}$, (f) $\mathrm{C}_{60} \mathrm{H}_{5}^{-}$, (g) $\mathrm{C}_{60} \mathrm{H}_{6}^{\cdot-}$, (h) $\mathrm{C}_{60} \mathrm{H}_{7}^{-}$.

leading, respectively, to $\mathrm{CD}_{2} \mathrm{OH}^{\bullet}$ and $\mathrm{CH}_{3} \mathrm{O}^{\bullet}$ formation, or some of the hydrogens added are exchanged over time with the $\mathrm{OH}$ group of the excess $\mathrm{CD}_{3} \mathrm{OH}$. Whatever the mechanism involved, the data are compatible with a maximum of 11 hydrogens added as derived from Figure 2 above.

The $\mathrm{C}_{60} \mathrm{H}_{\mathrm{u}} \mathrm{O}_{\mathrm{y}}^{-}(\mathrm{y}>0)$ ion intensities build up only at longer times (see Figure 5) and the corresponding fitted rate constants are therefore much smaller than those corresponding to hydride formation. The oxygen containing species might require $\mathrm{C}_{60} \mathrm{H}_{\mathrm{x}}^{-}$as intermediates. Based on the current data, no definitive conclusions can be drawn about the exact structure of the $\mathrm{C}_{60} \mathrm{H}_{\mathrm{x}} \mathrm{O}_{\mathrm{y}}^{-}$ anions. They are, however, expected to be related to fullerenols since oxidation of fullerene hydrides into fullerenols was found to occur in solution upon redissolution in water, $\mathrm{HCl}$, or pyridine [20] or in presence of $\mathrm{H}_{2} \mathrm{O}_{2}-\mathrm{NaOH}$ and HOAc [50].

The dehydrogenation of $\mathrm{C}_{60}$ hydride anions is demonstrated using IRMPA (Figure 2C-a and Figure 5A-b, $\mathrm{B}-\mathrm{b}, \mathrm{C}-\mathrm{b}$, and D-b). Upon IRMPA using a continuouswave $\mathrm{CO}_{2}$ laser, the hydrides and oxygen containing adducts stored in the ICR cell of the mass spectrometer and resulting from the reaction of $\mathrm{C}_{60}^{\cdot-}$ with methanol during $512 \mathrm{~s}$ yield back $\mathrm{C}_{60}^{\cdot-}$ isotopic distribution with only negligible $\mathrm{CH}_{\mathrm{x}}$ and $\mathrm{C}_{2} \mathrm{H}_{\mathrm{x}}$ losses (see Figure $2 \mathrm{C}$ ). The recovery rates of the ${ }^{12} \mathrm{C}_{60}^{--}$ion signal upon IRMPA (see Figure 5A-b, B-b, C-b, and D-b) also points to nondestructive hydrogen addition/removal processes. This suggests that the $\mathrm{C}_{60}$ cage remains intact with the oxygen containing adducts being hydroxyls [50]. Dehydrogenation is favored upon other reaction channels, since the relatively slow IRMPA process leads to selective dissociation through the lowest threshold channel [54]. No evidence of electron detachment from $\mathrm{C}_{60}^{--}$or its hydrides upon IRMPA was observed; the fluctuations observed in the $\mathrm{C}_{60}^{--}$signal intensities and thus in the signal recovery rates measured upon IRMPA have been assigned to small instabilities in the electrospray process.

From the dehydrogenation of $\mathrm{C}_{60} \mathrm{H}^{-}$and the spectra of Figure 5 (D-c and D-d), clearly one of the observed dissociation mechanism involves $\mathrm{H}^{\bullet}$ loss, in agreement with the theoretical predictions reported by Bettinger et al. [55]. This does not, however, preclude the parallel $\mathrm{H}_{2}$ loss mechanism. Indeed, the ion signals enriched in $\mathrm{C}_{60} \mathrm{H}_{2 \times}^{--}$after weak IRMPA could be explained either by a $\mathrm{H}_{2}$ loss or by two different $\mathrm{H}^{\bullet}$ loss rates, one for radical species, $\mathrm{C}_{60} \mathrm{H}_{2 \mathrm{x}}^{\cdot-}$, and another one for closedshell species, $\mathrm{C}_{60} \mathrm{H}_{2 \mathrm{x}+1}^{--}$. The presence of different isomers formed upon hydrogenation of $\mathrm{C}_{60}^{\cdot-}$ by methanol is also expected to affect the dehydrogenation process.

Provided that (1) energy relaxation processes are at least as fast as laser up-pumping for molecules near the dissociation threshold, (2) the dissociation kinetics are governed by the laser up-pumping processes near threshold and not by the rate of crossing a low-energy bottleneck, (3) collisional relaxation is unimportant compared with spontaneous radiative relaxation, the infrared multiphoton low-intensity regime corresponds to an incoherent stepwise thermal-like excitation [54, 56] leading to extensive internal energy randomization [57]. Since the previous assumptions are most likely to hold for a low-intensity $(\sim 20 \mathrm{~W})$ continuous wave laser $(10.6 \mu \mathrm{m})$, low-pressure $\left(10^{-14}\right.$ bar $)$ conditions, and large molecules with a quasi-continuum of vibrational states at room temperature $\left(\mathrm{C}_{60}\right.$ has about $10^{10}$ states per $\mathrm{cm}^{-1}$ at the average thermal energy of $0.5 \mathrm{eV}$, at $300 \mathrm{~K}$ $[58,59], \mathrm{C}_{60}^{--}$and its hydrides may be assumed to

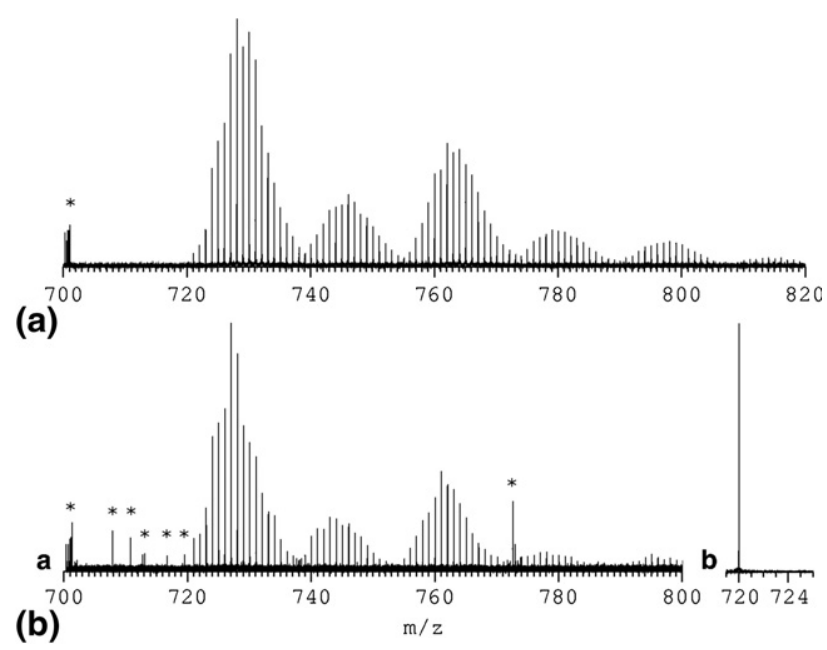

Figure 8. Mass spectra: (A) of the reaction products of all the isotopic contributions to $\mathrm{C}_{60}^{\cdot-}$ signal and (B-a) of ${ }^{12} \mathrm{C}_{60}^{\bullet-}$ signal [illustrated in (B-b)] with $\mathrm{CD}_{3} \mathrm{OH}$ for $320 \mathrm{~s}$ at room temperature $\left(20 \pm 1^{\circ} \mathrm{C}\right)$ at a pressure of about $0.1 \mathrm{~Pa}$. Formation of hydrides incorporating both $\mathrm{H}$ and $\mathrm{D}$ is observed. Deuterium incorporation supports $\mathrm{CD}_{3} \mathrm{OH}$ as the origin of the hydrogen atoms added to $\mathrm{C}_{60}$ (see text). Instrumental electronic artifacts $\left({ }^{*}\right)$ are more abundant in spectrum (B) due to the high-resolution mode used to attempt to resolve the (D) and $(\mathrm{H})$ contributions for a pure ${ }^{12} \mathrm{C}_{60}^{--}$signal. Resolution of hydrogen isotopes (H) pair versus (D) is, however, not feasible on the instrument used. 
undergo, upon IRMPA, a thermal-like dehydrogenation comparable to the thermal dehydrogenation previously reported $[7,9,16,60]$.

Whether it is possible or not to achieve higher hydrogenation levels using the current approach is not known. Two observations suggest that $11 \mathrm{H}$, however, might correspond to an upper limit. First, the electron affinity of the fullerene hydrides decreases as the number of hydrogen atoms increases, with fullerene hydrides containing a number of hydrogen atoms higher than 10-12 (and smaller than 18) reported to have negative electron affinities $[23,61]$. Secondly, no significant change in the maximum number of hydrogen atoms in the $\mathrm{C}_{60} \mathrm{H}_{\mathrm{x}}^{-}$ions is observed between the 256 and $512 \mathrm{~s}$ reaction times, whereas the proportion of oxygen containing species increases. This suggests that another reaction mechanism takes the relay, possibly involving the replacement of the hydrogen atoms added by hydroxyls.

\section{Conclusions}

Although the gas-phase approach is not practical to mass produce hydrides, it can provide useful mechanistic information using a tightly controlled environment. Mild $\mathrm{C}_{60}^{\cdot-}$ hydrogenation in the gas phase by reaction with methanol vapor was demonstrated for vapor pressures in the microbar range and room temperature conditions. The use of partially or fully deuterated methanol has been instrumental to validate the origin of the hydrogenation process. For the experimental conditions used, a maximum of 11 hydrogen atoms were added to $C_{60}^{\cdot-}$. This limitation seems to be governed by the electron affinity of the $\mathrm{C}_{60} \mathrm{H}_{n}$ species and by parallel hydroxylation reactions. The latter aspect could change upon using other hydrogen providing reactants. Kinetic studies are compatible with the assumption that only one hydrogen atom at a time is transferred to the fullerene or its hydrides upon reaction with methanol. For the longer reaction times, the formation of oxygen containing species competes with the hydride formation. The dehydrogenation of the fullerene hydride anions with recovery of $\mathrm{C}_{60}^{\bullet-}$ anions was successfully performed using low-intensity IRMPA with a $10.6 \mu \mathrm{m}$ continuous-wave $\mathrm{CO}_{2}$ laser. IRMPA was also found to lead to the successful removal of adducts such as hydroxyl or oxygen from fullerene anions. Based on the experimental evidence, a multistep mechanism for radical hydrogen loss is most probable, in agreement with previously published theoretical results [55]. Fullerene hydride anions, therefore, appear to be a potentially interesting source of hydrogen radicals and molecular hydrogen when irradiated by infrared radiation. Hydrogenation, dehydrogenation and catalytic studies taking place in the gas phase can help elucidate mechanisms taking place in other media and pertaining to hydrogen storage or direct methanol fuel cell applications.
This work is now being extended to higher alcohols, using a setup that allows better monitoring/controlling of the kinetic and internal energy distributions as well as accurate laser power measurements. These results will be reported in a subsequent paper.

\section{Acknowledgments}

The authors gratefully acknowledge FEDER (E2UR 12020000082430006) for funding.

\section{References}

1. Chen, P.; Wu, X.; Tan, K. L. High H2 Uptake by Alkali-Doped Carbon Nanotubes Under Ambient Pressure and Moderate Temperatures. Science 1999, 285, 91-93.

2. Liu, C.; Fan, Y. Y.; Liu, M.; Cong, H. T.; Cheng, H. M.; Dresselhaus, M. S. Hydrogen Storage in Single-Walled Carbon Nanotubes at Room Temperature. Science 1999, 286, 1127-1129.

3. Deluga, G. A.; Salge, J. R.; Schmidt, L. D.; Verykios, X. E. Renewable Hydrogen from Ethanol by Autothermal Reforming. Science 2004, 303, 993-997.

4. Baldé, C. P.; Hereijgers, B. P. C.; Bitter, J. H.; Jong, K. P. Sodium Alanate Nanoparticles-Linking Size to Hydrogen Storage Properties. J. Am. Chem. Soc. 2008, 130, 6761-6765.

5. Sunderlin, L. S.; Paulino, J. A.; Chow, J.; Kahr, B.; Ben-Amotz, D. Squires, R. R. Gas-Phase Reactivity of Fullerene Anions. J. Am. Chem. Soc. 1991, 113, 5489-5490.

6. Javahery, G.; Petrie, S.; Wincel, H.; Wang, J.; Bohme, D. K. Gas-Phase Reactions of the Buckminsterfullerene Cations C60,$+ \mathrm{C} 602+, \mathrm{C} 60 \bullet 3+$ with Water, Alcohols, and Ethers. J. Am. Chem. Soc. 1993, 115, 62956301.

7. Rüchardt, C.; Gerst, M.; Ebenhoch, J.; Beckhaus, H. D.; Campbell, E. E. B.; Tellgmann, R.; Weiske, T.; Pitter, S. Transfer Hydrogenation and Deuteration of Buckminsterfullerene C60 by 9,10-Dihydroanthracene and 9,9',10,10'[D4]Dihydroanthracene. Angew. Chem. Int. Ed. Engl. 1993, 32, 584-586.

8. Talyzin, A. V.; Tsybin, Y. O.; Schaub, T. M.; Mauron, P.; Shulga, Y. M.; Züttel, A.; Sundqvist, B.; Marshall, A. G. Composition of Hydrofullerene Mixtures Produced by C60 Reaction with Hydrogen Gas Revealed by High-Resolution Mass Spectrometry. J. Phys. Chem. B 2005, 109, 12742-12747

9. Darwish, A. D.; Abdul-Sada, A. K.; Langley, G. J.; Kroto, H. W.; Taylor, R.; Walton, D. R. M. Polyhydrogenation of [60]- and [70]-Fullerenes. J. Chem. Soc. Perkin Trans. 2 1995, 12, 2359-2365.

10. Darwish, A. D.; Avent, A. G.; Taylor, R.; Walton, D. R. M. Structural Characterization of $\mathrm{C} 60 \mathrm{H} 18$; a C3v Symmetry Crown. J. Chem. Soc. Perkin Trans. 2 1996, 10, 2051-2054.

11. Vasil'ev, Y.; Wallis, D.; Nüchter, M.; Ondruschka, B.; Lobach, A.; Drewello, T. From Major to Minor and Back-a Decisive Assessment of C60H36 with Respect to the Birch Reduction of C60. J. Chem. Soc. Chem. Commun. 2000, 14, 1233-1234.

12. Rogner, I.; Birkett, P.; Campbell, E. E. B. Hydrogenated and Chlorinated Fullerenes Detected by "Cooled" Modified Matrix-Assisted Laser Desorption Ionization Mass Spectroscopy (MALDI-MS). Int. J. Mass Spectrom. Ion Processes 1996, 156, 103-108.

13. Talyzin, A. V.; Tsybin, Y. O.; Purcell, J. M.; Schaub, T. M.; Shulga, Y. M. Noréus, D.; Sato, T.; Dzwilewski, A.; Sundqvist, B.; Marshall, A. G. Reaction of Hydrogen Gas with C60 at Elevated Pressure and Temperature: Hydrogenation and Cage Fragmentation. J. Phys. Chem. A 2006, $110,8528-8534$.

14. Vasil'ev, Y.; Hirsch, A.; Taylor, R.; Drewello, T. Hydrogen Storage on Fullerenes: Hydrogenation of C59N Using C60H36 as the Source of Hydrogen. Chem. Commun. 2004, 15, 1752-1753.

15. Haufler, R. E.; Conceicao, J.; Chibante, L. P. F.; Chai, Y.; Byrne, N. E.; Flanagan, S.; Haley, M. M.; O’Brien, S. C.; Pan, C.; Xiao, Z.; Billups, W. E.; Ciufolini, M. A.; Hauge, R. H.; Margrave, J. L.; Wilson, L. J.; Curl, R. F.; Smalley, R. E. Efficient Production of C60 (Buckminsterfullerene), C60H36, and the Solvated Buckide Ion. J. Phys. Chem. 1990, 94, $8634-$ 8636.

16. Bank, M. R.; Dale, M. J.; Gosney, I.; Hodgson, P. K. G.; Jennings, R. C. K.; Jones, A. C.; Lecoultre, J.; Langridge-Smith, P. R. R.; Maier, J. P.; Scrivens, J. H.; Smith, M. J. C.; Smyth, C. J.; Taylor, A. T.; Thorburn, P.; Webster, A. S. Birch Reduction of C60-a New Appraisal. J. Chem. Soc. Chem. Commun. 1993, 14, 1149-1152.

17. Peera, A.; Saini, R. K.; Alemany, L. B.; Billups, W. B.; Saunders, M.; Khong, A.; Syamala, M. S.; Cross, R. J. Formation, Isolation, and Spectroscopic Properties of Some Isomers of C60H38, C60H40, C60H42, and $\mathrm{C} 60 \mathrm{H} 44$ - Analysis of the Effects of the Different Shapes of Various Helium-Containing Hydrogenated Fullerenes on Their 3He Chemical Shifts. Eu. J. Org. Chem. 2003, 4140-4145. 
18. Briggs, J. B.; Montgomery, M. N.; Silva, L. L.; Miller, G. P. Facile, Scalable, Regioselective Synthesis of C3v C60H18 Using Organic Polyamines. Org. Lett. 2005, 7, 5553-5555.

19. Kintigh, J.; Briggs, J. B.; Letourneau, K.; Miller, G. P. Fulleranes Produced via Efficient Polyamine Hydrogenations of [60]Fullerene, [70]Fullerene, and Giant Fullerenes. J. Mater. Chem. 2007, 17, 4647-4651.

20. Avent, A. G. Darwish, A. D * Hemibach, D. K. Kroto, H. W. Meidine, M. F.; Parsons, J. P.; Remars, C.; Roers, R.; Ohashi, O.; Taylor, R.; Walton, D. R. M. Formation of Hydrides of Fullerene-C60 and Fullerene-C70. J. Chem. Soc. Perkin Trans. 2 1994, 1, 15-22.

21. Henderson, C. C.; Cahill, P. A. C60H2: Synthesis of the Simplest C60 Hydrocarbon Derivative. Science 1993, 259, 1885-1887.

22. Henderson, C. C.; Rohlfing, C. M.; Assink, R. A.; Cahill, P. A. C60H4: Kinetics and Thermodynamics of Multiple Addition to C60. Angew. Chem. Int. Ed. Engl. 1994, 33, 786-788.

23. Vasil'ev Y. V.; Absalimov, R. R.; Nasibullaev, S. K.; Lobach, A. S.; Drewello, T. Formation and Characterization of Long-lived Negative Molecular Ions of C60H18. J. Phys. Chem. A 2001, 105, 661-665.

24. Gerst, M.; Beckhaus, H. D.; Rüchardt, C.; Campbell, E. E. B.; Tellgmann, R. [7H]Benzanthrene, a Catalyst for the Transfer Hydrogenation of C60 and C70 by 9,10-Dihydroanthracene. Tetrahedron Lett. 1993, 34, 77297732.

25. Fukuzumi, S.; Suenobu, T.; Kawamura, S.; Ishida, A.; Mikami, K. Selective Two-Electron Reduction of C60 by 10-Methyl-9,10Dihydroacridine via Photoinduced Electron Transfer. J. Chem. Soc. Chem. Commun. 1997, 3, 291-292.

26. Becker, L.; Evans, T.; Bada, J. L. Synthesis of $\mathrm{C} 60 \mathrm{H} 2$ by RhodiumCatalyzed Hydrogenation of C60. J. Org. Chem. 1993, 58, 7630-7631.

27. Talyzin, A. V.; Shulga, Y. M.; Jacob, A. Comparative Study of Hydrofullerides $\mathrm{C} 60 \mathrm{Hx}$ Synthesized by Direct and Catalytic Hydrogenation. App. Phys. A 2004, 78, 1005-1010.

28. Osaki, T.; Tanaka, T.; Tai, Y. Hydrogenation of C60 on AluminaSupported Nickel and Thermal Properties of C60H36. Phys. Chem. Chem. Phys. 1999, 1, 2361-2366.

29. Meier, M. S.; Corbin, P. S.; Vance, V. K.; Clayton, M.; Mollman, M.; Poplawska, M. Synthesis of Hydrogenated Fullerenes by Zinc/Acid Reduction. Tetrahedron Lett. 1994, 35, 5789-5792.

30. Darwish, A. D.; Abdul-Sada, A. K.; Langley, G. J.; Kroto, H. W.; Taylor, R.; Walton, D. R. M. Polyhydrogenation of [60]- and [70]Fullerenes with $\mathrm{Zn} / \mathrm{HCl}$ and $\mathrm{Zn} / \mathrm{DCl}$. Synth. Met. 1996, 77, 303-307.

31. Meier, M. S.; Weedon, B. R.; Spielmann, H. P. Synthesis and Isolation of One Isomer of C60H6. J. Am. Chem. Soc. 1996, 118, 11682-11683.

32. Bergosh, R. G.; Meier, M. S.; Cooke, J. A. L.; Spielmann, H. P.; Weedon, B. R. Dissolving Metal Reductions of Fullerenes. J. Org. Chem. 1997, 62, 7667-7672.

33. Meier, M. S.; Spielmann, H. P.; Haddon, R. C.; Bergosh, R. G.; Gallagher, M. E.; Hamon, M. A.; Weeden, B. R. Reactivity, Spectroscopy, and Structure of Reduced Fullerenes. Carbon 2000, 38, 1535-1538.

34. Ballenweg, S.; Gleiter, R.; Krätschmer, W. Hydrogenation of Buckminsterfullerene C60 via Hydrozirconation: A New Way to Organofullerenes. Tetrahedron Lett. 1993, 34, 3737-3740.

35. Attalla, M. L.; Vassalo, A. M.; Tattam, B. N.; Hana, J. V. Preparation of Hydrofullerenes by Hydrogen Radical Induced Hydrogenation. J. Phys. Chem. 1993, 97, 6329-6331.

36. Cliffel, D. E.; Bard, A. J. Electrochemical Studies of the Protonation of C60- and C60(2-). J. Phys. Chem. 1994, 98, 8140-8143.

37. Niyazymbetov, M. E.; Evans, D. H.; Lerke, S. A.; Cahill, P. A.; Henderson, C. C. Study of Acid-Base and Redox Equilibria for the $\mathrm{C} 60 / \mathrm{C} 60 \mathrm{H} 2$ System in Dimethyl Sulfoxide Solvent. J. Phys. Chem. 1994, 98, 1309313098

38. Nozu, R.; Matsumoto, O. Hydrogenation of $\mathrm{C} 60$ by Electrolysis of KOH-H2O Solution. J. Electrochem. Soc. 1996, 143, 1919-1923.

39. Mandrus, D.; Kele, M.; Hettich, R. L.; Guiochon, G.; Sales, B. C.; Boatner, L. A. Sonochemical Synthesis of C60H. J. Phys. Chem. B 1997, 101, 123-128

40. Jin, C.; Hettich, R.; Compton, R.; Joyce, D.; Blencoe, J.; Buch, T. Direct Solid-Phase Hydrogenation of Fullerenes. J. Phys. Chem. 1994, 98, 4215-4217.
41. Vieira, S. M. C.; Ahmed, W.; Birkett, P. R.; Rego, C. A. Hydrogenation of [60]Fullerene Using a Novel Chemical Vapor Modification (CVM) Method. Chem. Phys. Lett. 2001, 347, 355-360.

42. Wågberg, T.; Johnels, D.; Peera, A.; Hedenstroem, M.; Shulga, Y. M.; Tsybin, Y. O.; Purcell, J. M.; Marshall, A. G.; Noreus, D.; Sato, T.; Talyzin, A. V. Selective Synthesis of the C3v Isomer of C60H18. Org Lett. 2005, 7, 5557-5560.

43. Talyzin, A. V.; Dzwilewski, A.; Sundqvist, B.; Tsybin, Y. O.; Purcell, J. M.; Marshall, A. G.; Shulga, Y. M.; McCammon, C.; Dubrovinsky, L. Hydrogenation of C60 at 2 GPa Pressure and High Temperature. Chem. Phys. 2006, 325, 445-451.

44. Howard, J. A. EPR, FTIR, and FAB Mass Spectrometric Investigation of Reaction of H Atoms with C60 in a Cyclohexane Matrix. Chem. Phys. Lett. 1993, 203, 540-544.

45. Brühweiler, P. A.; Anderson, S.; Dippel, M.; Mårtenson, N.; Demirev, P. A.; Sundqvist, U. R. Hydrogenation of Solid C60 by Atomic Hydrogen. Chem. Phys. Lett. 1993, 214, 45-49.

46. Nossal, J.; Saini, R. K.; Alemany, L. B.; Meier, M.; Billups, W. E. The Synthesis and Characterization of Fullerene Hydrides. Eur. J. Org. Chem. 2001, 22, 4167-4180.

47. Dorozhko, P. A.; Lobach, A. S.; Popov, A. A.; Senyavin, V. M.; Korobov, M. V. Sublimation of Hydrofullerenes C60H36 and C60H18. Chem. Phys. Lett. 2001, 336, 39-46.

48. Wang, N. X.; Zhang, J. P. Preparation of C60H36. J. Phys. Chem. A 2006 $110,6276-6278$

49. Liang, Z.; Marshall, A. G. Precise Relative Ion Abundances from Fourier Transform Ion Cyclotron Resonance Magnitude-Mode Mass Spectra. Anal. Chem. 1990, 62, 70-75.

50. Schneider, N. S.; Darwish, A. D.; Kroto, H. W.; Taylor, R.; Walton, D. R. M. Formation of Fullerols via Hydroboration of Fullerene-C60. J. Chem. Soc. Chem. Commun. 1994, 4, 463-464.

51. Jusys, Z.; Behm, R. J. Methanol Oxidation on a Carbon-Supported Pt Fuel Cell Catalyst-A Kinetic and Mechanistic Study by Differential Electrochemical Mass Spectrometry. J. Phys. Chem. B 2001, 105, $10874-$ 10883.

52. Maiwald, T.; Timmer, J. Dynamical Modeling and Multi-Experiment Fitting with PottersWheel. Bioinformatics 2008, 24, 2037-2043.

53. Tsang, W. Energetics of Organic Free Radicals. In Heats of Formation of Organic Free Radicals by Kinetic Methods, Martinho Simoes, J. A.; Greenberg, A.; Liebman, J. F., Eds.; Blackie Academic and Professional: London, 1996; pp 22-58.

54. Bomse, D. S.; Woodin, R. L.; Beauchamp, J. L. Molecular Activation with Low-Intensity CW Infrared Laser Radiation. Multiphoton Dissociation of Ions Derived from Diethyl Ether. J. Am. Chem. Soc. 1979, 101 5503-5512.

55. Bettinger, H. F.; Rabuck, A. D.; Scuseria, G. E.; Wang, N. X.; Litosh, V. A.; Saini, R. K.; Billups, W. E. Pathways for the Thermally Induced Dehydrogenation of $\mathrm{C} 60 \mathrm{H} 2$. Chem. Phys. Lett. 2002, 360, 509-514.

56. Woodin, R. L.; Bomse, D. S.; Beauchamp, J. L. Multiphoton Dissociation of Molecules with Low Power Continuous Wave Infrared Laser Radiation. J. Am. Chem. Soc. 1978, 100, 3248-3250.

57. Dunbar, R. C. Kinetics of Low-Intensity Infrared Laser Photodissociation. The Thermal Model and Application of the Tolman Theorem. J. Chem. Phys. 1991, 95, 2537-2548.

58. Haufler, R. E.; Wang, L. S.; Chibante, L. P. F.; Jin, C.; Conceicao, J.; Chai Y.; Smalley, R. E. Fullerene Triplet State Production and Decay: R2PI Probes of C60 and C70 in a Supersonic Beam. Chem. Phys. Lett. 1991, 179, $449-454$

59. Andersen, J. U.; Hvelplund, P.; Nielsen, S. B.; Pedersen, U. V.; Tomita, S. Statistical Electron Emission After Laser Excitation of C60-Ions from an Electrospray Source. Phys. Rev. A 2002, 65, 053202, 1-6.

60. Billups, W. E.; Gonzalez, A.; Gesenberg, C.; Luo, W.; Marriott, T. Alemany, L. B.; Saunders, M.; Jiménez-Vázquez, H. A.; Khong, A. $3 \mathrm{He}$ NMR Spectra of Highly Reduced C60. Tetrahedron Lett. 1997, 38, 175-178.

61. Matsuzawa, N.; Fukunaga, T.; Dixon, D. A. Electronic Structures of 1,2 and 1,4-C60X2n Derivatives with $n=1,2,4,6,8,10,12,18,24$, and 30 . J. Phys. Chem. 1992, 96, 10747-10756. 